\title{
NGHIÊN CỬU XÂY DỤ̂NG BẢN ĐỒ CHI TIẾT CÂPP Độ RỦI RO DO NGẬP LỤT HẠ LƯU SÔNG KÔN - HÀ THANH
}

\author{
Nguyễn Văn Lý1, Bùi Văn Chanh ${ }^{1}$
}

Tóm tắt: Cấp độ rủi ro do lũ lụt quy định trong Quyết định 44/2014/QĐ-TTg ngày 15 tháng 8 năm 2014 của Thủ tuớng Chính phủ được quy đổi tù cấp mực nước các trạm thủy văn nên chura chi tiết. Vì cùng một mực nước nhung độ sâu ngập ở các vùng khác nhau nên rủi ro khác nhau, ngoài ra ở nhũ̃ng vùng có độ sâu ngập nhu nhau nhưng mức độ phát triển kinh tế xã hội khác nhau nên rủi ro cũng khác nhau. Do đó, để nâng cao độ tin cậy về cảnh báo rủi ro do ngập lut cần xây dụng bản đồ chi tiết theo không gian. Trong nghiên cưu này đã thư nghiệm chi tiết cấp độ rủi ro do ngập lụt cho hạ lưu sông Kôn - Hà Thanh dưa trên Quyết định 44 và chi tiết bản đồ chỉ số rủi ro dụa trên quan điểm của IPCC, phuoong pháp AHP. Bản đồ chi tiết chỉ số rủi ro hạ luu sông Kôn - Hà Thanh được xây dưng tù bản đồ chi tiết ngập lut và số liệu điều tra xã họi học. Các kịch bản ngập hạ lưu sông Kôn - Hà Thanh kết hợp với số liệu điều tra xã học xây dưng được bản đồ chi tiết cấp độ rủi ro do ngập lụt ưng với các tần suất 1\%,3\%, 5\%, 10\%, vỡ đập Định Bình ứng với lũ thiết kế và lu kiểm tra.

Từ khóa: Rủi ro do ngập lụt, Cấp độ rủi ro, Sông Kôn - Hà Thanh.

Ban Biên tập nhận bài: 11/2/2020 Ngày phản biện xong: 20/3/2020 Ngày đăng bài: 25/3/2020

\section{1. Đặt vấn đề}

Cấp độ rủi ro thể hiện mức độ nguy hiểm của thiên tai đối với tính mạng, tài sản, công trình dân sinh kinh tế xã hội; có vai trò quyết định trong công tác phòng chống ứng phó và được nhiều quốc gia sử dụng. Ở nước ta, cấp độ ro thiên tai được quy định trong Quyết định số 44/2014/QĐ-TTg ngày 15 tháng 8 năm 2014 của Thủ tướng Chính phủ về quy định chi tiết cấp độ rủi ro thiên tai, từ đó quy định trách nhiệm của Ban chỉ huy Phòng chống thiên tai và Tìm kiếm cứu nạn các cấp thông qua Nghị định 160/2018/NĐ-CP ngày 29 tháng 11 năm 2018. Phục vụ tốt công tác phòng chống thiên tai ở địa phương, trong các bản tin cảnh báo, dự báo thời tiết thủy văn nguy hiểm phải cảnh báo cấp độ rủi thiên tai theo quy định. Tuy nhiên cấp độ rủi ro do ngập lụt trong Quyết định 44 quy đổi từ mực nước các trạm thủy văn nên cấp độ rủi ro của toàn bộ vùng ngập là như nhau, không phù hợp. Trong thực tế, cùng một mực nước tại trạm thủy văn nhưng độ sâu ngập, tốc độ dòng chảy trong vùng ngập và thời gian duy trì ngập khác nhau nên cấp độ rủi ro do ngập khác nhau. Mặt khác, với các vùng có cùng độ sâu, tốc độ và thời gian ngập nhưng mức độ phát triển kinh tế, khả năng phòng chống ứng phó, mức độ và thời gian khôi phục lại đời sống, sản xuất khác nhau nên cấp độ rủi ro khác nhau. Như vậy, cấp độ rủi ro ngập lụt phụ thuộc vào mức độ và quy mô ngập lụt, tính nhạy và khả năng chống chịu với ngập lụt, mức độ phơi nhiễm và ảnh hưởng của tài sản trước nguy cơ ngập lụt.

Hạ lưu sông Kôn - Hà Thanh có diễn biến ngập phức tạp, mức độ phát triển kinh tế xã hội không đồng điều, đây là lưu vực điển hình cho khu vực Nam Trung Bộ thể hiện mức độ phân bố mạnh theo không gian về rủi ro do ngập lụt. Hạ lưu sông Kôn - Hà Thanh được lựa chọn thí điểm phân cấp độ chi tiết cấp độ rủi ro ngập lụt. Để xác định cơ sở khoa học và thực tiễn phục vụ tính toán chi tiết cấp độ rủi ro ngập lụt cho hạ lưu sông Kôn - Hà Thanh, nghiên cứu đã phân tích lựa chọn phương pháp tính rủi ro thiên tai 
do IPCC đề xuất [6], sử dụng phương pháp phân tích hệ thống thứ bậc (AHP) [1] để tính trọng số trong công thức cộng của IPCC.

Các thành phần rủi ro thiên tai trong công thức của IPCC gồm: hiểm họa, dễ bị tổn thương và phơi nhiễm (hình 1 ). Tùy thuộc mức độ ảnh hưởng, tầm quan trọng của mỗi thành phần rủi ro trong công thức cộng của IPCC để xác định trọng số từng thành phần. Phương pháp AHP được chia thành 9 mức độ quan trọng, mỗi thành phần được xác định mức độ quan trọng tương ứng với thang chia trên để xác định trọng số. Mỗi thành phần trên gồm nhiều yếu tố, mỗi yếu tố cũng có trọng số được xác định bằng phương pháp AHP để tính chỉ số thành phần bằng công thức cộng.

Thành phần hiểm họa là ngập lụt gồm các yếu tố độ sâu, vận tốc, thời gian, các yếu tố này được xây dựng thành bản đồ ngập gồm 3 lớp trên từ kết quả mô phỏng của mô hình Mike Flood. Bản đồ ngập lụt hạ lưu sông Kôn - Hà Thanh được mô phỏng bằng mô hình Mike Flood từ bản đồ địa hình tỷ lệ 1/10.000 hệ tọa độ VN2000, 37 mặt cắt ngang [4], kịch bản mưa lũ ứng với tần suất $1 \%, 3 \%, 5 \%, 10 \%$, vỡ đập Định Bình ứng với lũ thiết kế và kiểm tra. Các kịch bản mưa lũ ứng với các tần suất gồm lưu lượng từ trạm Bình Tường, hồ Định Bình, cầu Phú Phong, trạm Diêu Trì; mực nước tại các cửa ra ở đầm Thị Nại được tính từ trạm triều Quy Nhơn; lượng mưa gia nhập khu giữa được tính từ trạm khí tượng Quy Nhơn, An Nhơn. Đối với trường hợp vỡ đập được tính theo hồ sơ thiết kế hồ Định Bình và mô hình sóng vỡ đập để tính toán lưu lượng về hạ du. Các kịch bản các yếu tố đầu vào trên được tổ hợp cùng tần suất để xây dựng bản đồ ngập lụt hạ lưu sông Kôn - Hà Thanh. Mô hình Mike Flood vùng hạ lưu sông Kôn - Hà Thanh được hiệu chỉnh và kiểm định trước khi mô phỏng các kịch bản ngập trên với chất lượng theo chỉ tiêu Nash từ 78,5 - 89,3\% đạt loại tốt theo tiêu chuẩn của WMO [5].

Thành phần tính dễ bị tổn thương gồm các yếu tố tính nhạy và khả năng chống chịu được xác định bằng phiếu điều tra xã hội học, niên giám thống kê. Yếu tố tính nhạy được xác định từ các chỉ số dân số, lao động, thu nhập, dân trí, nghề nghiệp, kinh tế, điều kiện sống, cơ sở hạ tầng, môi trường. Yếu tố khả năng chống chịu được xác định từ các chỉ số về khả năng và kinh nghiệm chống lũ, nhu yếu phẩm, thông tin và mức độ phản ứng khi xảy ra lũ, khả năng hỗ trợ của xã hội và cộng đồng, khả năng bảo vệ tài sản và khôi phục sản suất. Tính nhạy càng cao tỷ lệ thuận với tổn thương, chống chịu tỷ lệ nghịch với tổn thương. Các thành phần và yếu tố được tính toán bằng công thức cộng với các trọng số kèm theo. Các trọng số được xác định bằng phương pháp AHP tương tự như thành phần ngập lụt ở trên. Phiếu điều tra gồm bộ câu hỏi để người dân tự trả lời, đối tượng được điều tra gồm nhiều thành phần khác nhau về nghề nghiệp, trình độ, hoàn cảnh kinh tế. Phiếu điều tra cán bộ xã gồm các thông tin về phòng chống ứng phó, thiệt hại của các xã, mỗi xã gồm 01 phiếu điều tra cán bộ xã và 18 phiếu điều tra người dân. Vùng hạ lưu sông Kôn - Hà Thanh có 57 xã, điều tra được 1083 phiếu [5].

Thành phần phơi nhiễm của rủi ro đặc trưng cho mức độ lộ diện và ảnh hưởng của tài sản, con người trước hiểm họa. Việc xác định đối tượng, khối lượng, giá trị tài sản phục vụ tính toán thành phần phơi nhiễm rất phức tạp và khó khăn do nhiều loại tài sản biến động theo thời gian như giao thông, hoa màu, hàng hóa. Để tính toán chỉ số của thành phần phơi nhiễm cần được trung bình hóa sự biến đổi theo thời gian, tài sản thường được sử dụng, cất giữ, xây dựng ở một nơi nào đó. Khu vực thành thị là nơi có giá trị tài sản cao hơn nông thôn, trong thành phố thì khu vực sản xuất kinh doanh có giá trị tài sản cao hơn khu dân cư. Do đó để đơn gian hóa xác định độ phơi nhiễm, cần sử dụng bản đồ sử dụng đất và mã hóa thuộc tính theo mức độ quan trọng, mục đích sử dụng của từng loại đất. Mức độ quan trọng như sau: (6) Đất an ninh quốc phòng, (5) Đất công cộng, (4) Đất ở và đô thị, (3) Đất nông nghiệp, (2) Đất rừng và cây công nghiệp, (1) Đất trống và sông ngòi [1]. 


\section{BÀI BÁO KHOA HỌC}

\section{Phương pháp chi tiết cấp độ rủi ro ngập lụt}

Rủi ro thiên tai được định nghĩa là khả năng xảy ra các thay đổi nghiêm trọng trong các chức năng bình thường của một cộng đồng hay một xã hội ở một giai đoạn thời gian cụ thể, do các hiểm họa tự nhiên tương tác với các điều kiện dễ bị tổn thương của xã hội, dẫn đến các ảnh hưởng bất lợi rộng khắp đối với con người, vật chất, kinh tế hay môi trường, đòi hỏi phải ứng phó khẩn cấp để đáp ứng các nhu cầu cấp bách của con người và có thể phải cần đến sự hỗ trợ từ bên ngoài để phục hồi [2]. Rủi ro thiên tai xuất hiện từ việc kết hợp giữa hiểm họa và tính dễ bị tổn thương của các yếu tố bị phơi nhiễm trước hiểm họa, làm tăng khả năng không thực hiện các chức năng bình thường của xã hội khi thiên tai xảy ra [2].

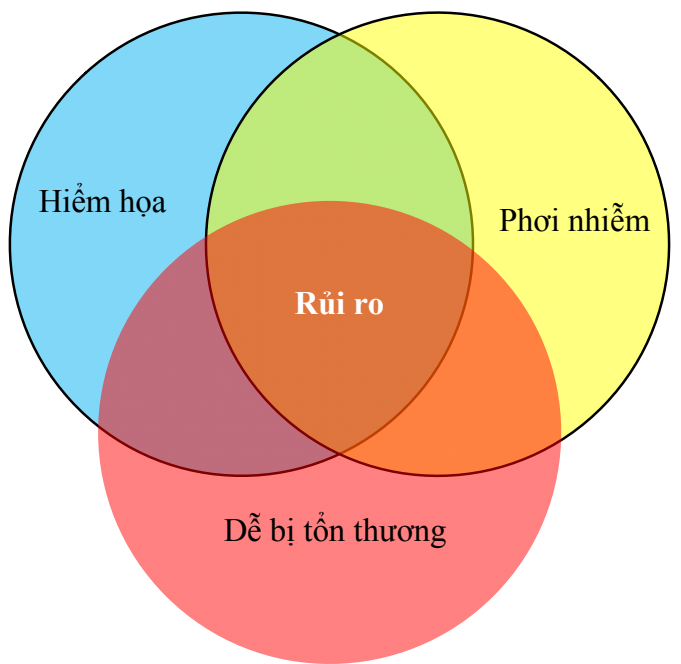

Hình 1. Minh họ các thành phần rủi ro thiên tai

Từ quan điểm và khái niệm trên, phương pháp xác định chỉ số rủi ro là hàm của hiểm họa, độ phơi nhiễm và tính dễ bị tổn thương; trong đó tính dễ bị tổn thương là hàm của tính nhạy và khả năng chống chịu theo công thức sau [5]:

$$
\begin{gathered}
R=f(H, E, V) \\
V=f(S, A)
\end{gathered}
$$

Trong đó $\mathrm{R}$ là chỉ số rủi ro thiên tai (Risk); $\mathrm{H}$ là hiểm họa (thiên tai) (Hazard); E là độ phơi nhiễm (Exposure); V là giá trị tính dễ bị tổn thương (Vulnerability); S là tính nhạy (Sensitivity); A là khả năng chống chịu (Adaptivity $\mathrm{Ca}$ pacity).
Công thức tính chỉ số rủi ro thiên tai theo quan hệ 1 và 2 theo công thức tổng cho ngập lụt như sau [1]:

$$
R=\sum_{i=1}^{n} X_{i} w_{i}
$$

Trong đó $\mathrm{R}$ là chỉ số rủi ro ngập lụt; $\mathrm{X}_{\mathrm{i}}$ là giá trị các thành phần; $\mathrm{w}_{\mathrm{i}}$ là trọng số các thành phần; $\mathrm{n}$ là tổng thành phần.

Từ công thức (3) thu được công thức tính chỉ số rủi ro ngập lụt như sau [5]:

$$
\mathrm{R}_{\mathrm{j}}=\mathrm{H}_{\mathrm{j}}{ }^{*} \mathrm{~W}_{\mathrm{H}}+\mathrm{E}_{\mathrm{j}}{ }^{*} \mathrm{~W}_{\mathrm{E}}+\mathrm{V}_{\mathrm{j}}{ }^{*} \mathrm{WV}_{\mathrm{V}}
$$

Trong đó $R_{j}$ chỉ số rủi ro ngập lụt vùng $\mathrm{j} ; \mathrm{H}_{\mathrm{j}}$ chỉ số thành phần ngập lụt vùng $\mathrm{j} ; \mathrm{E}_{\mathrm{j}}$ chỉ số thành phần phơi nhiễm vùng $\mathrm{j} ; \mathrm{V}_{\mathrm{j}}$ chỉ số dễ bị tổn thương ngập lụt vùng $\mathrm{j}$; $\mathrm{w}_{\mathrm{H}}, \mathrm{W}_{\mathrm{E}}, \mathrm{w}_{\mathrm{V}}$ là trọng số của 3 thành phần trên (tổng giá trị 3 trọng số = $1)$.

Chỉ số thành phần dễ bị tổn thương gồm 02 yếu tố tính nhạy và khả năng chống chịu được tính toán theo công thức cộng như sau [5]:

$$
\mathrm{V}_{\mathrm{j}}=\mathrm{S}_{\mathrm{j}}{ }^{*} \mathrm{Ws}_{\mathrm{s}}+\mathrm{A}_{\mathrm{j}}{ }^{*} \mathrm{~W}_{\mathrm{A}}
$$

Trong đó $\mathrm{V}_{\mathrm{j}}$ là chỉ số dễ bị tổn thương ngập lụt vùng $\mathrm{j} ; \mathrm{S}_{\mathrm{j}}$ là chỉ số yếu tố tính nhạy vùng $\mathrm{j} ; \mathrm{A}_{\mathrm{j}}$ là chỉ số khả năng chống chịu vùng $\mathrm{j}$; ws, wA là trọng số của 2 yếu tố trên (tổng giá trị 2 trọng số $=1)$.

Chỉ số thành phần hiểm họa do ngập lụt được tính toán theo công thức cộng như sau [5]:

$$
\mathrm{H}_{\mathrm{j}}=\mathrm{H}_{1 \mathrm{j}} * \mathrm{~W}_{1}+\mathrm{H}_{2 \mathrm{j}} * \mathrm{~W}_{2}+\mathrm{H}_{3 \mathrm{j}} * \mathrm{~W}_{3}
$$

Trong đó $\mathrm{H}_{\mathrm{j}}$ là chỉ số hiểm họa do ngập lụt vùng $\mathrm{j} ; \mathrm{H}_{1 \mathrm{j}}$ là chỉ số yếu tố độ sâu ngập vùng $\mathrm{j}$; $\mathrm{H}_{2 \mathrm{j}}$ là chỉ số yếu tố tốc độ dòng chảy vùng $\mathrm{j} ; \mathrm{H}_{3 \mathrm{j}}$ là chỉ số yếu tố thơi gian ngập vùng $\mathrm{j} ; \mathrm{w}_{1}, \mathrm{w}_{2}, \mathrm{w}_{3}$ là trọng số của 3 yếu tố trên (tổng giá trị 2 trọng số bằng 1).

Sử dụng phương pháp đánh giá chỉ số phát triển con người (HDI) của UNDP (2006) để chuẩn hóa các yếu tố của các thành phần hiểm họa, phơi bảy, tính nhạy và khả năng chống chịu, cụ thể như sau [1]:

$$
X_{i, j}=\frac{X_{i, j}-\operatorname{Min} X_{i, j}}{\operatorname{Max}_{i, j}-\operatorname{Min}_{i, j}}
$$

+ Hàm quan hệ thuận với tính dễ bị tổn thương và chuẩn hóa biểu diễn bằng công thức: 


$$
X_{i, j}=\frac{\operatorname{Max}_{i, j}-X_{i, j}}{\operatorname{Max}_{i, j}-\operatorname{MinX}_{i, j}}
$$

Mặt khác khi xem xét đên các biên mà giá trị của biến càng cao thì khả năng gây tổn thương càng thấp thì công thức đối với hàm quan hệ nghịch sẽ là:

Trong đó $\mathrm{x}_{\mathrm{ij}}$ là giá trị điểm thứ $\mathrm{j}$ thuộc biến thứ $\mathrm{i}$ đã chuẩn hóa; $X_{\mathrm{ij}}$ là giá trị điểm thứ $\mathrm{j}$ thuộc biến thứ i chưa chuẩn hóa; $\operatorname{Max}\left\{X_{i j}\right\}$ là giá trị lớn nhất thuộc biến thứ $\mathrm{i}$ chưa chuẩn hóa; $\operatorname{Min}\left\{X_{i j}\right\}$ là giá trị nhỏ nhất thuộc biến thứ i chưa chuẩn hóa.

Sử dụng phương pháp AHP để tính trọng số các yếu tố của các thành phần hiểm họa, phơi nhiễm, tính nhạy và khả năng chống chịu. Phương pháp phân tích hệ thống thứ bậc - AHP (Analytic Hierarchy Process) được Saaty đề xuất vào những năm 1970 và đã được nhiều nghiên cứu mở rộng, bổ sung cho đến nay [7]. Phương pháp AHP đã được áp dụng rộng rãi cho nhiều lĩnh vực như khoa học tự nhiên, kinh tế, xã hội, y tế... Nó được dùng như một công cụ linh hoạt để phân tích quyết định với nhiều tiêu chí, cho phép nhìn thấy rõ ràng các tiêu chí thẩm định và quyết định nhiều thuộc tính, trong đó đề cập đến một kỹ thuật định lượng. Sử dụng AHP là để định lượng các ưu tiên về chất lượng giữa các thành phần chính, phụ cũng như các chỉ số và thể loại. So sánh cặp của một tập các đối tượng hoặc tiêu chuẩn hoặc lựa chọn thay thế) được sử dụng để xác định trọng số của các thành phần. Phân tích hệ thống phân cấp (AHP) như là một cấu trúc mô hình hóa với các quyết định chủ quan, bao gồm: mục tiêu tổng quát, nhóm các tùy chọn/lựa chọn thay thế để đạt được mục tiêu và nhóm các yếu tố hoặc các tiêu chuẩn có liên quan đến lựa chọn/thay thế các mục tiêu ấy. Quá trình cơ bản của AHP dựa trên cơ sở nhận thức, phân tích và tổng hợp. Mục đích là để cung cấp một phương pháp cho mô hình hóa các vấn đề phi cấu trúc trong các ngành khoa học kinh tế, xã hội và quản lý. Hệ thống phân cấp cấu trúc trừu tượng của một hệ thống nhằm nghiên cứu sự tương tác giữa các thành phần của hệ thống và tác động của chúng lên toàn hệ thống. Sự trừu tượng này có thể mang theo một số hình thức liên quan, tất cả hình thức đều hình thành một mục tiêu chung, đến mục tiêu phụ cho đến những người ảnh hưởng của các yếu tố này, các mục tiêu của con người và sau đó đến chính sách của họ, xa hơn là các chiến lược, và cuối cùng sẽ thu được kết quả từ những chiến lược đó [8]. AHP có 3 bước thực hiện: phân tích, so sánh và tổng hợp độ ưu tiên [1].

* Trọng số các yếu tố trong thành phần tính nhạy được thể hiện ở bảng dưới đây:

Bảng 1. Trọng số thành phần tính nhạy

\begin{tabular}{ccccccccc}
\hline $\begin{array}{c}\text { Thành } \\
\text { phần }\end{array}$ & S.nk1 & S.nk2 & S.nk3 & S.nk4 & S.nk5 & S.nk6 & S.nk7 \\
$\begin{array}{c}\text { Trọng } \\
\text { số } \\
\text { Thành } \\
\text { phần }\end{array}$ & 0.09 & 0.11 & 0.18 & 0.19 & 0.21 & 0.12 & 0.1 \\
$\begin{array}{c}\text { Trọng } \\
\text { số } \\
\text { Thành } \\
\text { phần }\end{array}$ & 0.21 & S.cs1 & S.cs2 & S.cs3 & S.cs4 & S.cs5 & S.mt1 & S.mt2 \\
$\begin{array}{c}\text { Trọng } \\
\text { số } \\
\text { Thành }\end{array}$ & 0.28 & 0.16 & 0.20 & 0.20 & 0.16 & 0.19 & 0.21 \\
phần & S.mt3 & S.mt4 & Snk & Ssk & Scs & Smt & \\
$\begin{array}{c}\text { Trọng } \\
\text { số }\end{array}$ & 0.31 & 0.29 & 0.28 & 0.29 & 0.22 & 0.21 & \\
\hline
\end{tabular}

* Trọng số các yếu tố trong thành phần khả năng chống chịu được thể hiện ở bảng dưới đây: 


\section{BÀI BÁO KHOA HỌC}

Bảng 2. Trọng số thành phần khả năng chống chịu

\begin{tabular}{cccccccc}
\hline $\begin{array}{c}\text { Thành } \\
\text { phần }\end{array}$ & A.dk1 & A.dk2 & A.dk3 & A.dk4 & A.dk5 & A.dk6 & A.kn1 \\
\hline $\begin{array}{c}\text { Trọng } \\
\text { số }\end{array}$ & 0.18 & 0.09 & 0.21 & 0.11 & 0.20 & 0.21 & 0.39 \\
$\begin{array}{c}\text { Thành } \\
\text { phần }\end{array}$ & A.kn2 & A.kn3 & A.ht1 & A.ht2 & A.ht3 & A.kp1 & A.kp2 \\
$\begin{array}{c}\text { Trọng } \\
\text { số }\end{array}$ & 0.29 & 0.32 & 0.22 & 0.30 & 0.48 & 0.21 & 0.30 \\
$\begin{array}{c}\text { Thành } \\
\text { phần }\end{array}$ & A.kp3 & A.kp4 & Adk & Akn & Aht & Akp & \\
$\begin{array}{c}\text { Trọng } \\
\text { số }\end{array}$ & 0.29 & 0.20 & 0.24 & 0.26 & 0.28 & 0.22 & \\
\hline
\end{tabular}

* Trong công thức tính hiểm họa: Độ sâu ngập lụt: 0.58 ; Vận tốc dòng chảy trong vùng ngập: 0.17 ; Thời gian duy trì: 0.25 . * Trong công thức tính tổn thương: Tính 0.33 . nhạy: 0.57; Khả năng chống chịu: 0.43 .

* Trong công thức tính chỉ số rủi ro: Hiểm họa: 0.42; Phơi bày: 0.25; Tính dễ bị tổn thương:

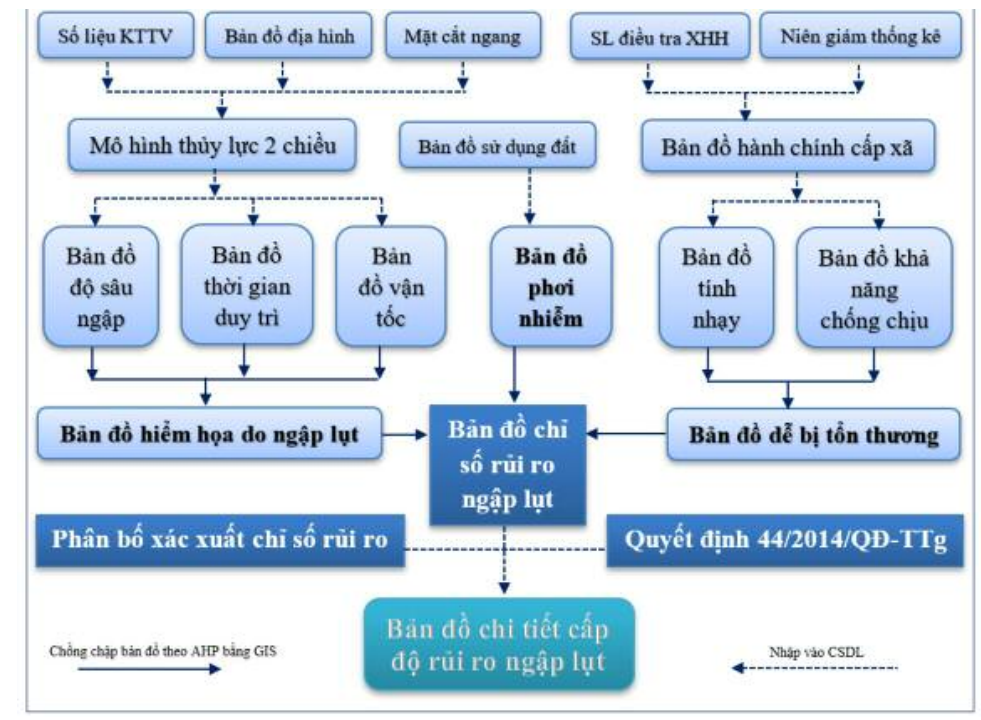

Hình 2. So đồ khối quá trình chi tiết cấp độ rủi ro do ngập lụt

\section{Kết quả và thảo luận}

\subsection{Kết quả tính toán chi tiết hóa cấp độ rủi} ro do ngập lụt cho sông Kôn-Hà Thanh

Chi tiết cấp độ rủi ro ngập lụt hạ lưu sông Kôn - Hà Thanh được thực hiện từ các yếu tố của từng thành phần trên. Mỗi yếu tố được số hóa trên bản đồ ngập, sử dụng đất, hành chính cấp xã và cắt nhỏ các vùng (vùng $\mathrm{j}$ ở trên) bằng phương pháp chồng chập bản đồ. Sử dụng công thức cộng ở trên để tính thuộc tính giữa các trường dữ liệu các yếu tố thành phần trên cho từng vùng bằng phần mềm MapInfo 15.0. Xây dựng bộ chỉ số rủi ro ngập lụt gồm các bước: 1 - Lựa chọn vùng nghiên cứu; 2 - Thiết lập bộ tiêu chí; 3 Chuẩn hóa các biến số; 4 - Xác định các trọng số; 5 - Tính giá trị chỉ số rủi ro ngập lụt; 6 - Xây dựng bản đồ chỉ số rủi ro ngập lụt; 7 - Xác định cấp độ rủi ro ngập lụt trên cơ sở phân ngưỡng bộ chỉ số; 8 - Xây dựng bản đồ chi tiết cấp độ rủi ro ngập lụt [1]. 
Bảng 3. Minh họa kết quả tính toán chỉ số thành phần một vài nút

\begin{tabular}{|c|c|c|c|c|c|c|c|c|}
\hline $\begin{array}{c}\text { Mảnh } \\
\mathrm{j}\end{array}$ & Xã & $\begin{array}{l}\text { Độ } \\
\text { sâu }\end{array}$ & $\begin{array}{l}\text { Vận } \\
\text { tốc }\end{array}$ & $\begin{array}{l}\text { Thời } \\
\text { gian }\end{array}$ & Snk & Scs & Adk & Akp \\
\hline 597 & $\begin{array}{c}\text { Phuoc } \\
\text { Son }\end{array}$ & 0.08 & 0.09 & 0.27 & 0.34 & 0.64 & 0.58 & 0.32 \\
\hline 598 & $\begin{array}{l}\text { Binh } \\
\text { Hoa }\end{array}$ & 0.23 & 0.30 & 0.31 & 0.29 & 0.52 & 0.25 & 0.36 \\
\hline 601 & $\begin{array}{l}\text { Binh } \\
\text { Hoa }\end{array}$ & 0.29 & 0.30 & 0.31 & 0.29 & 0.52 & 0.25 & 0.36 \\
\hline 602 & $\begin{array}{l}\text { Binh } \\
\text { Hoa }\end{array}$ & 0.23 & 0.16 & 0.31 & 0.29 & 0.52 & 0.25 & 0.36 \\
\hline 609 & $\begin{array}{c}\text { Nhon } \\
\text { Hoa }\end{array}$ & 0.03 & 0.02 & 0.57 & 0.37 & 0.65 & 0.51 & 0.43 \\
\hline 610 & $\begin{array}{l}\text { Nhon } \\
\text { Hoa }\end{array}$ & 0.39 & 0.50 & 0.57 & 0.37 & 0.65 & 0.51 & 0.43 \\
\hline 612 & $\begin{array}{l}\text { Nhon } \\
\text { Hoa }\end{array}$ & 0.39 & 0.50 & 0.57 & 0.37 & 0.65 & 0.51 & 0.43 \\
\hline 613 & $\begin{array}{l}\text { Tay } \\
\text { Vinh }\end{array}$ & 0.54 & 0.50 & 0.20 & 0.38 & 0.54 & 0.42 & 0.52 \\
\hline 626 & $\begin{array}{c}\text { Binh } \\
\text { Thanh }\end{array}$ & 0.23 & 0.36 & 0.37 & 0.37 & 0.54 & 0.33 & 0.39 \\
\hline 628 & $\begin{array}{l}\text { Nhon } \\
\text { Thanh }\end{array}$ & 0.59 & 0.70 & 0.21 & 0.33 & 0.65 & 0.55 & 0.44 \\
\hline 629 & $\begin{array}{l}\text { Nhon } \\
\text { Thanh }\end{array}$ & 0.59 & 0.64 & 0.21 & 0.33 & 0.65 & 0.55 & 0.44 \\
\hline 632 & $\begin{array}{l}\text { Nhon } \\
\text { Thanh }\end{array}$ & 0.34 & 0.36 & 0.21 & 0.33 & 0.65 & 0.55 & 0.44 \\
\hline 633 & $\begin{array}{l}\text { Nhon } \\
\text { Thanh }\end{array}$ & 0.29 & 0.30 & 0.21 & 0.33 & 0.65 & 0.55 & 0.44 \\
\hline 634 & $\begin{array}{l}\text { Cat } \\
\text { Tien }\end{array}$ & 0.29 & 0.30 & 0.48 & 0.55 & 0.66 & 0.50 & 0.71 \\
\hline 635 & $\begin{array}{l}\text { Cat } \\
\text { Tien }\end{array}$ & 0.29 & 0.36 & 0.48 & 0.55 & 0.66 & 0.50 & 0.71 \\
\hline 641 & $\begin{array}{c}\text { Cat } \\
\text { Chanh }\end{array}$ & 0.59 & 0.57 & 0.42 & 0.29 & 0.64 & 0.55 & 0.76 \\
\hline 642 & $\begin{array}{c}\text { Cat } \\
\text { Chanh }\end{array}$ & 0.64 & 0.64 & 0.42 & 0.29 & 0.64 & 0.55 & 0.76 \\
\hline 645 & $\begin{array}{l}\text { Nhon } \\
\text { Hanh }\end{array}$ & 0.59 & 0.70 & 0.74 & 0.30 & 0.55 & 0.69 & 0.66 \\
\hline 646 & $\begin{array}{l}\text { Nhon } \\
\text { Hanh }\end{array}$ & 0.59 & 0.64 & 0.74 & 0.30 & 0.55 & 0.69 & 0.66 \\
\hline 653 & $\begin{array}{c}\text { TT.Dieu } \\
\text { Tri }\end{array}$ & 0.49 & 0.64 & 0.24 & 0.29 & 0.54 & 0.46 & 0.19 \\
\hline 654 & $\begin{array}{l}\text { P.Nhon } \\
\text { Binh }\end{array}$ & 0.18 & 0.23 & 0.27 & 0.43 & 0.56 & 0.47 & 0.20 \\
\hline 655 & $\begin{array}{c}\text { P.Nhon } \\
\text { Binh }\end{array}$ & 0.29 & 0.36 & 0.27 & 0.43 & 0.56 & 0.47 & 0.20 \\
\hline
\end{tabular}

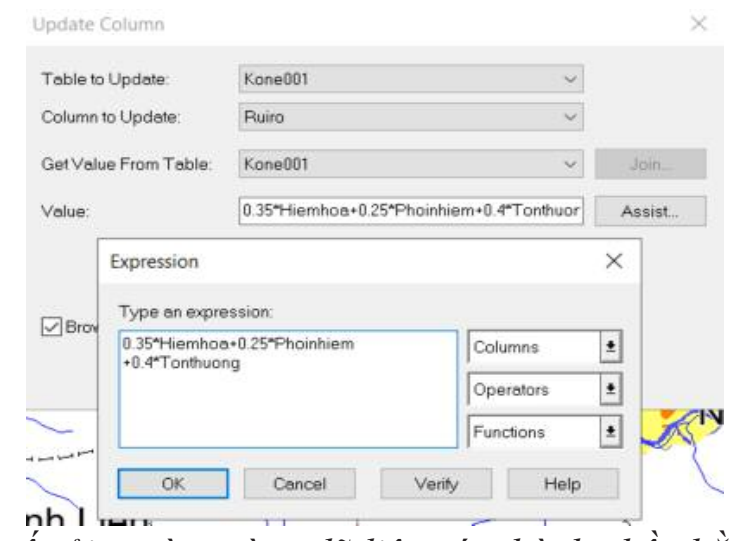

Hình 3. Tính chỉ số rủi ro tù̀ trường dĩ liệu các thành phần bằng MapInfo 15.0 
Bảng 4. Minh họa kết quả tính toán chỉ số tổng hợp một vài nút

\begin{tabular}{|c|c|c|c|c|c|c|c|c|}
\hline $\begin{array}{c}\text { Mảnh } \\
\mathrm{j}\end{array}$ & Xã & $\begin{array}{l}\text { Hiểm } \\
\text { họa }\end{array}$ & $\begin{array}{c}\text { Phơi } \\
\text { nhiễm }\end{array}$ & $\begin{array}{l}\text { Tính } \\
\text { nhạy }\end{array}$ & $\begin{array}{c}\text { Chống } \\
\text { chịu }\end{array}$ & $\begin{array}{c}\text { Tốn } \\
\text { thương }\end{array}$ & $\begin{array}{c}\text { Rủi } \\
\text { ro }\end{array}$ & $\begin{array}{l}\text { Câp } \\
\text { dộ }\end{array}$ \\
\hline 6218 & $\begin{array}{l}\text { Cat } \\
\text { Tan }\end{array}$ & 0.36 & 0.40 & 0.49 & 0.52 & 0.50 & 0.42 & 3 \\
\hline 6221 & $\begin{array}{l}\text { Cat } \\
\text { Tan }\end{array}$ & 0.20 & 0.40 & 0.49 & 0.46 & 0.48 & 0.34 & 2 \\
\hline 6222 & $\begin{array}{l}\text { Nhon } \\
\text { Tho }\end{array}$ & 0.36 & 0.60 & 0.51 & 0.49 & 0.50 & 0.48 & 3 \\
\hline 6223 & $\begin{array}{l}\text { Nho } \\
\text { Thar }\end{array}$ & 0.53 & 0.80 & 0.50 & 0.60 & 0.54 & 0.61 & 4 \\
\hline 6224 & & 0.14 & & 0.51 & 0.38 & 0.46 & 0.37 & 2 \\
\hline 6225 & $\begin{array}{c}\mathrm{Nh} \\
\mathrm{Th}\end{array}$ & 0.15 & 0.60 & 0.51 & 0.38 & 0.46 & 0.38 & 2 \\
\hline 6226 & $\begin{array}{l}\text { Nhon } \\
\text { My }\end{array}$ & 0.14 & & 0.55 & 0.51 & 0.53 & 0.46 & 3 \\
\hline 6227 & $\begin{array}{l}\text { Phuc } \\
\text { Loo }\end{array}$ & 0.19 & & 0.43 & 0.7 & .39 & 0.37 & 2 \\
\hline 6229 & & 0.15 & 0.60 & 0.51 & 0.38 & 0.46 & 0.38 & 2 \\
\hline 6230 & & 0.26 & & 0. & 0.43 & 0.49 & 0.37 & 2 \\
\hline 6231 & & 0.24 & 0.40 & 0.53 & & 0.49 & 0.36 & 2 \\
\hline 6232 & $\begin{array}{l}\mathrm{T} i \\
\mathrm{~A}\end{array}$ & 0.19 & & 0.38 & 0.33 & 0.36 & 0.42 & 3 \\
\hline 6233 & $\begin{array}{l}\mathrm{T} \\
\mathrm{A}\end{array}$ & & & & & 0.36 & & 3 \\
\hline 6234 & $\begin{array}{c}\mathrm{N} \\
\mathrm{L}\end{array}$ & 0.39 & 0.40 & 0.52 & 0.58 & 0.54 & 0.44 & 3 \\
\hline 6235 & & & & & & & & 3 \\
\hline 6236 & $\begin{array}{l}\text { Nhon } \\
\text { My }\end{array}$ & 0.06 & 0.40 & 0.55 & 0.4 & 0.53 & 0.30 & 2 \\
\hline 6237 & & 0.40 & & 0.38 & 0.38 & 0.38 & 0.46 & 3 \\
\hline 6238 & & 0.34 & & 0.60 & 0.59 & 0.60 & 0.44 & 3 \\
\hline 6239 & & 0.36 & 0.40 & 0.49 & 0.43 & 0.46 & 0.40 & 3 \\
\hline 6240 & & 0.32 & 0.00 & 0.38 & 0.34 & 0.36 & 0.24 & 1 \\
\hline 6241 & $\begin{array}{l}\text { Tay } \\
\text { Phu }\end{array}$ & 0.31 & 0.00 & 0.38 & 0.34 & 0.36 & 0.23 & 1 \\
\hline 6242 & & 0.33 & 0.60 & 0.52 & 0.48 & 0.50 & 0.46 & 3 \\
\hline 6243 & $\begin{array}{c}\text { Nhon } \\
\text { Loc }\end{array}$ & 0.54 & 0.60 & 0.52 & 0.64 & 0.57 & 0.57 & 3 \\
\hline
\end{tabular}

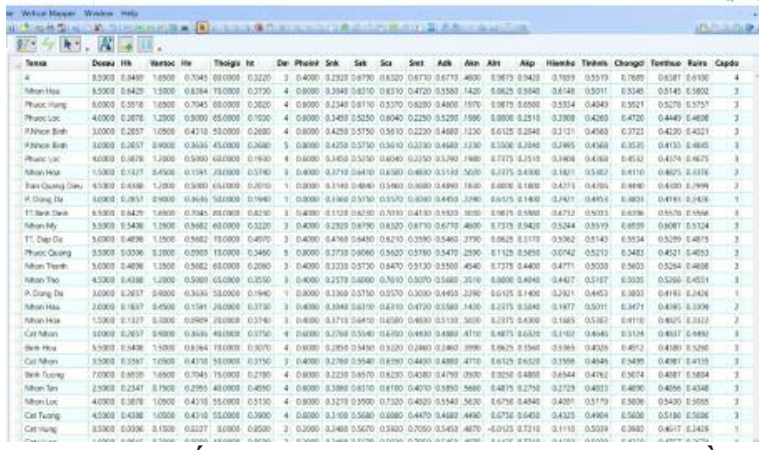

Hình 4. Kết quả tính chỉ số rủi ro truờng dũ liệu thành phần của các vùng 


\section{BÀI BÁO KHOA HỌC}
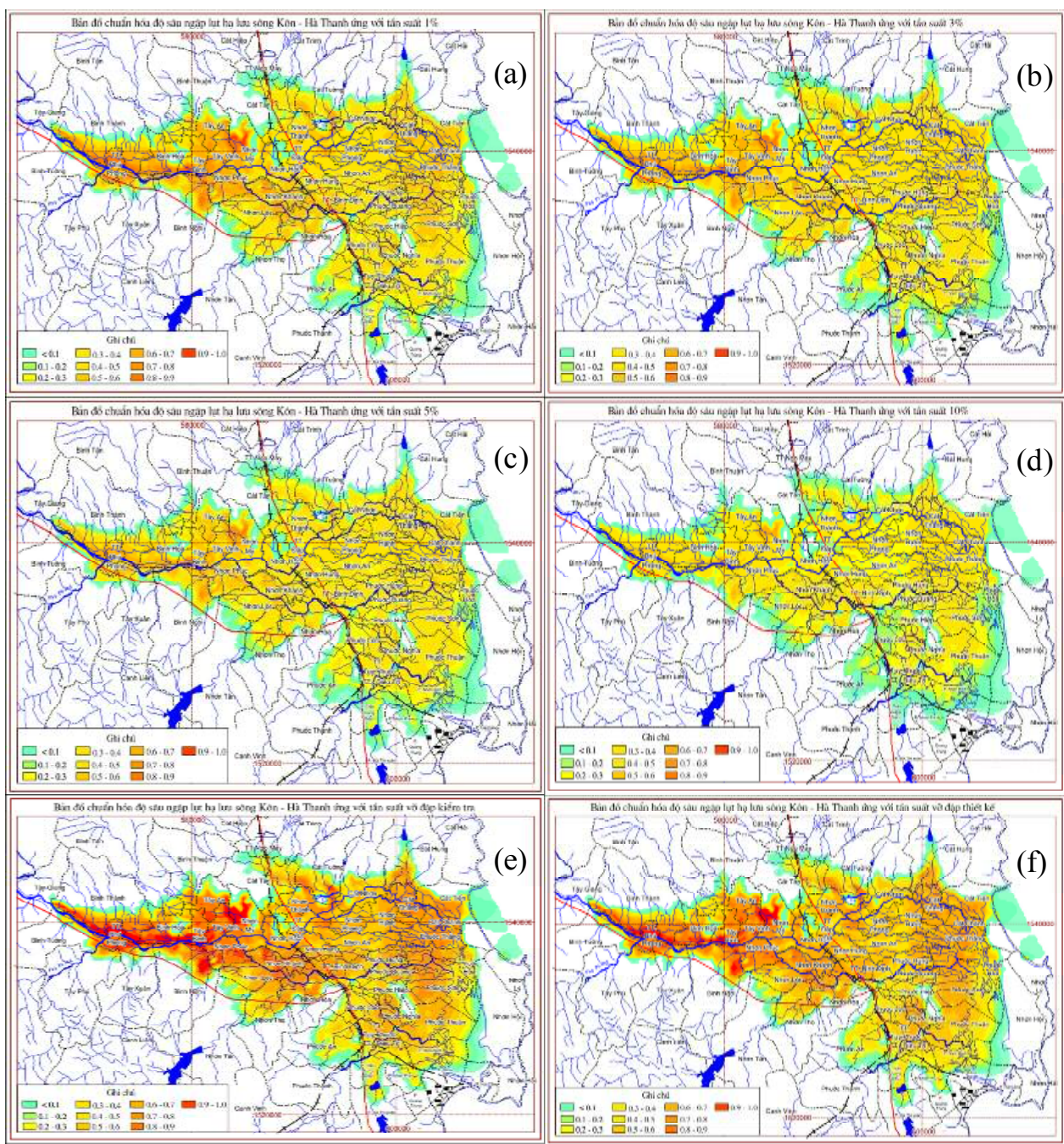

Hình 5. Bản đồ chỉ số ngập lụt: (a) Tần suất 1\%; (b) Tần suất 3\%; (c) Tần suất 5\%; (d) Tần suất 10\%; (e) Tần suất võ đập kiểm tra; (f) Tần suất võ đập thiết kế
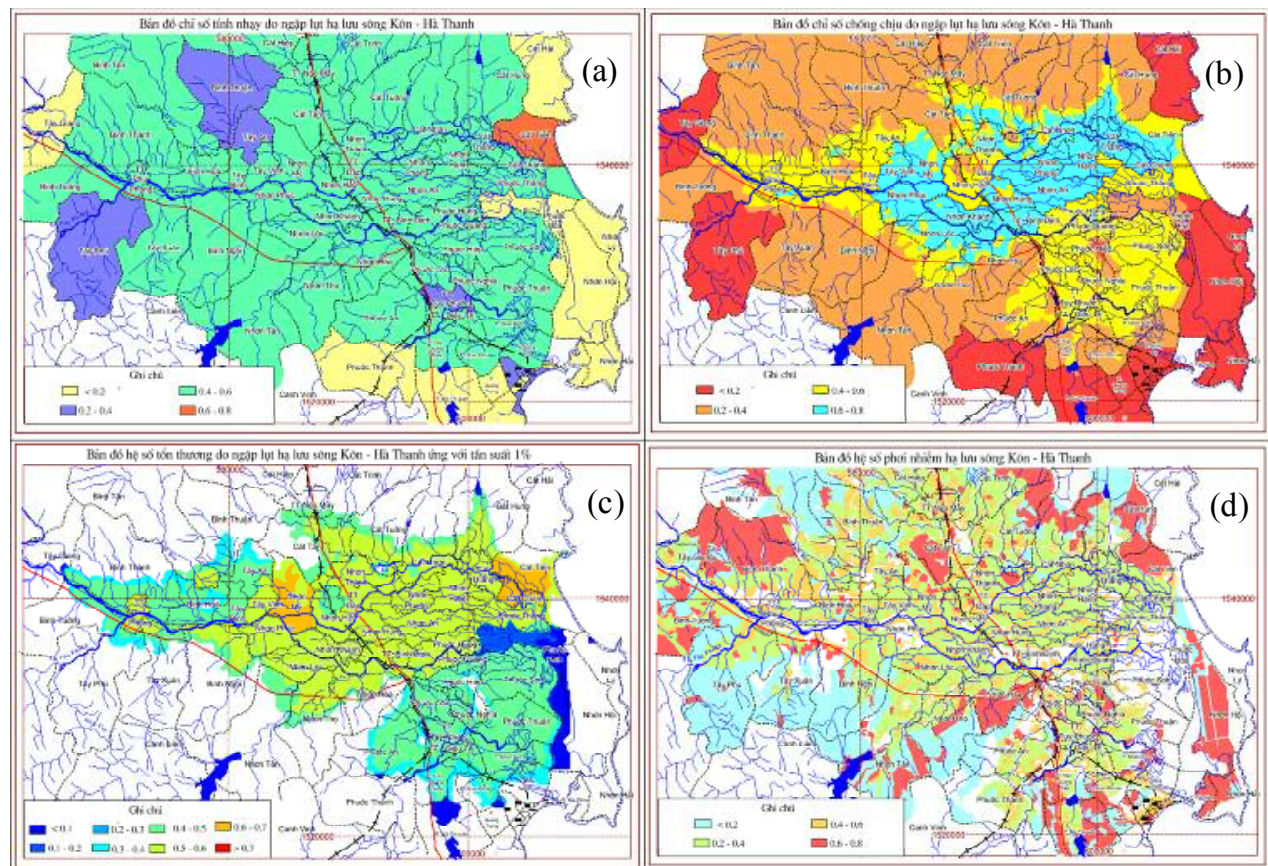

Hình 6. (a) Bản đồ chi số tính nhạy; (b) Bản đồ chỉ số chống chịu; (c) Bản đồ chỉ số dễ bi tổn thương; (d) Bản đồ chi số độ phơi nhiễm do ngập lụt hạ lưu sông Kôn - Hà Thanh 


\section{BÀI BÁO KHOA HỌC}

Từ bản đồ các chỉ số thành phần rủi ro, sử dụng công thức (4) chồng bản đồ bằng Map-

Info được bản đồ chỉ số rủi ro như sau [5]:
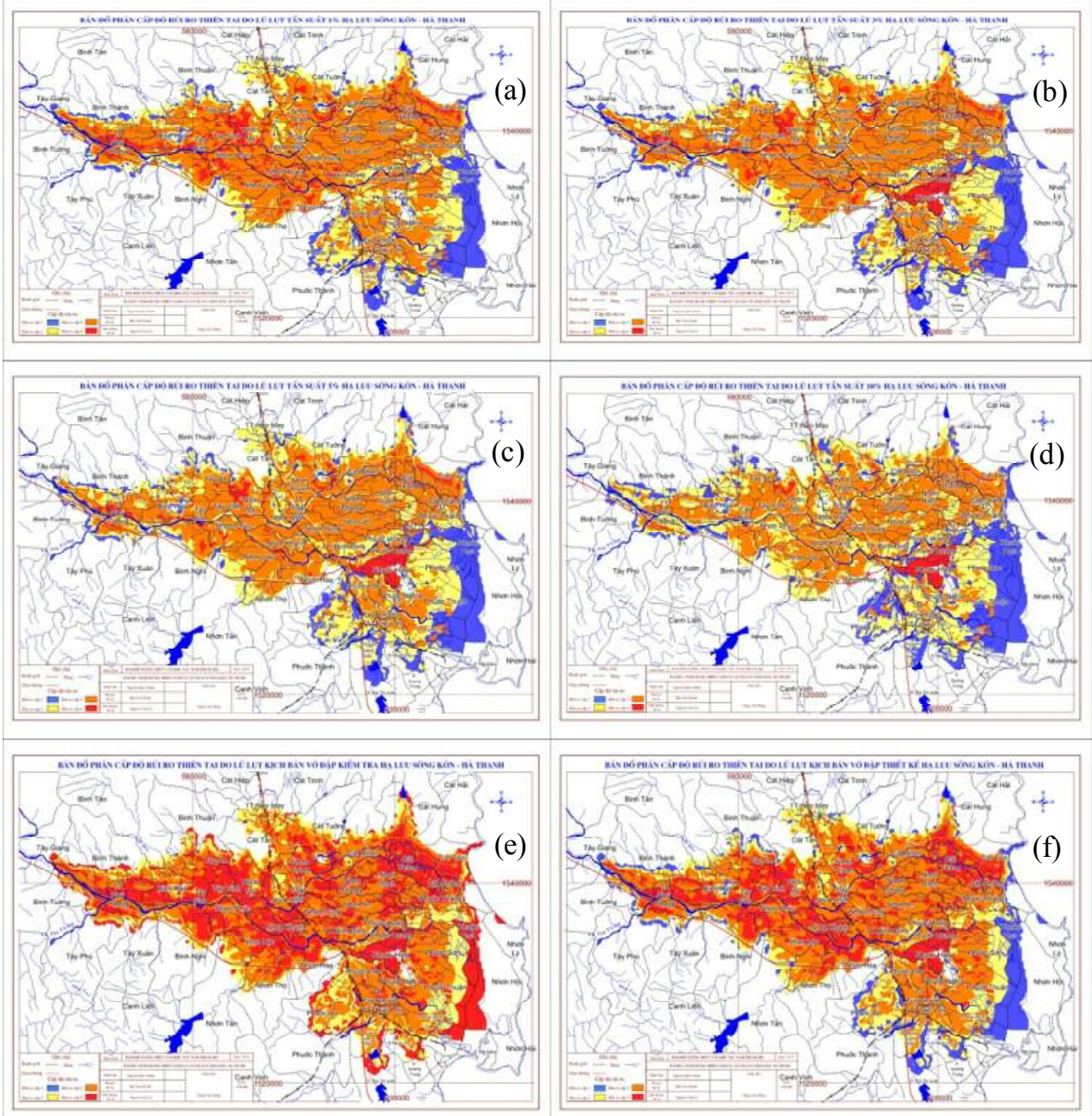

Hình 7. Bản đồ chỉ số rủi ro: (a) Tần suất 1\%; (b) Tần suất 3\%; (c) Tần suất 5\%; (d) Tần suất 10\%; (e) Ngập lut kịch bản vỡ đập kiểm tra; (f) Ngập lụt kịch bản vỡ đập thiết kế

\subsection{Kết quả chi tiết cấp độ rủi ro do ngập lüt}

Cấp độ rủi ro thiên tai được chia thành 5 cấp theo Quyết định 44, mỗi cấp có giá trị màu tương ứng như sau: (1) Cấp 1: màu xanh dương nhạt là rủi ro nhỏ, (2) Cấp 2: màu vàng nhạt là rủi ro trung bình, (3) Cấp 3: màu da cam là rủi ro lớn, (4) Cấp 4: màu đỏ là rủi ro rất lớn, (5) Cấp 5: màu tím là thảm họa. Bản đồ chi tiết cấp độ rủi ro ngập lụt hạ lưu sông Kôn-Hà Thanh được xây dựng từ bản đồ chỉ số rủi và phân ngưỡng chỉ số bằng hàm phân bố xác xuất nhị thức [3] dựa trên Quyết định 44 (Hình 9).

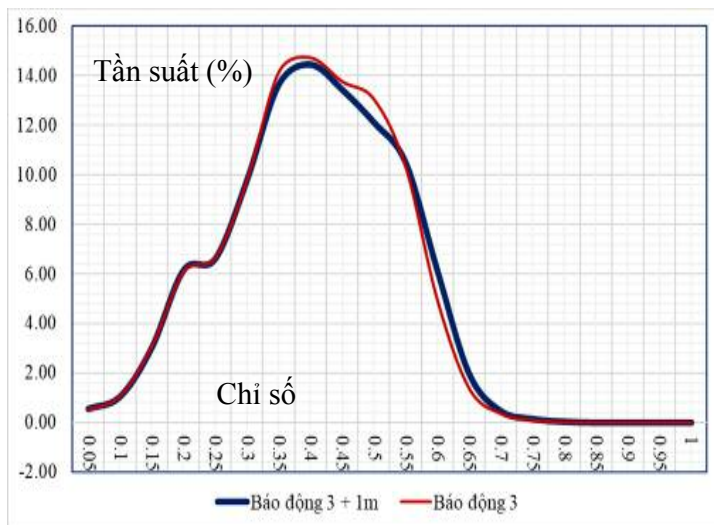

Hình 8. Phân bố xác suất nhi thức liên tuc

Từ kết quả vẽ phân bố xác xuất nhị thức liên tục cho thấy tại mức chỉ số rủi ro 0.27 và tần suất $6,66 \%$ trở lên tần suất tăng ổn định và đạt cao 
nhất ứng với tần suất từ 14.5 - 15,0\% ở mức chỉ số rủi ro là 0.40 (Hình 8 ). Ở mức chỉ số rủi ro 0,60 ứng với tần suất $6,66 \%$ có xu thể giảm có quy luật rõ ràng. Trong khoảng chỉ số từ 0.40 đến 0.60 xuất hiện các giá trị số đông, số giữa, tâm phân phối (trung bình số học) của phân bố xác xuất nhị thức liên tục [3]. Với kết quả phân bố xác suất như trên, kết hợp với Quyết định 44 , đề tài phân ngưỡng chỉ số rủi ro để xác định cấp độ rủi ro ngập lụt hạ lưu sông Kôn - Hà Thanh như sau [5]:

* Chỉ số rủi ro ngập lụt nhỏ hơn hoặc bằng 0,27: Rủi ro cấp 1

* Chỉ số rủi ro ngập lụt từ 0,27 đến 0,40 : Rủi ro cấp 2

* Chỉ số rủi ro ngập lụt từ 0,40 đến 0,60 : Rủi ro cấp 3

* Chỉ số rủi ro ngập lụt lớn hơn 0,60: Rủi ro cấp 4
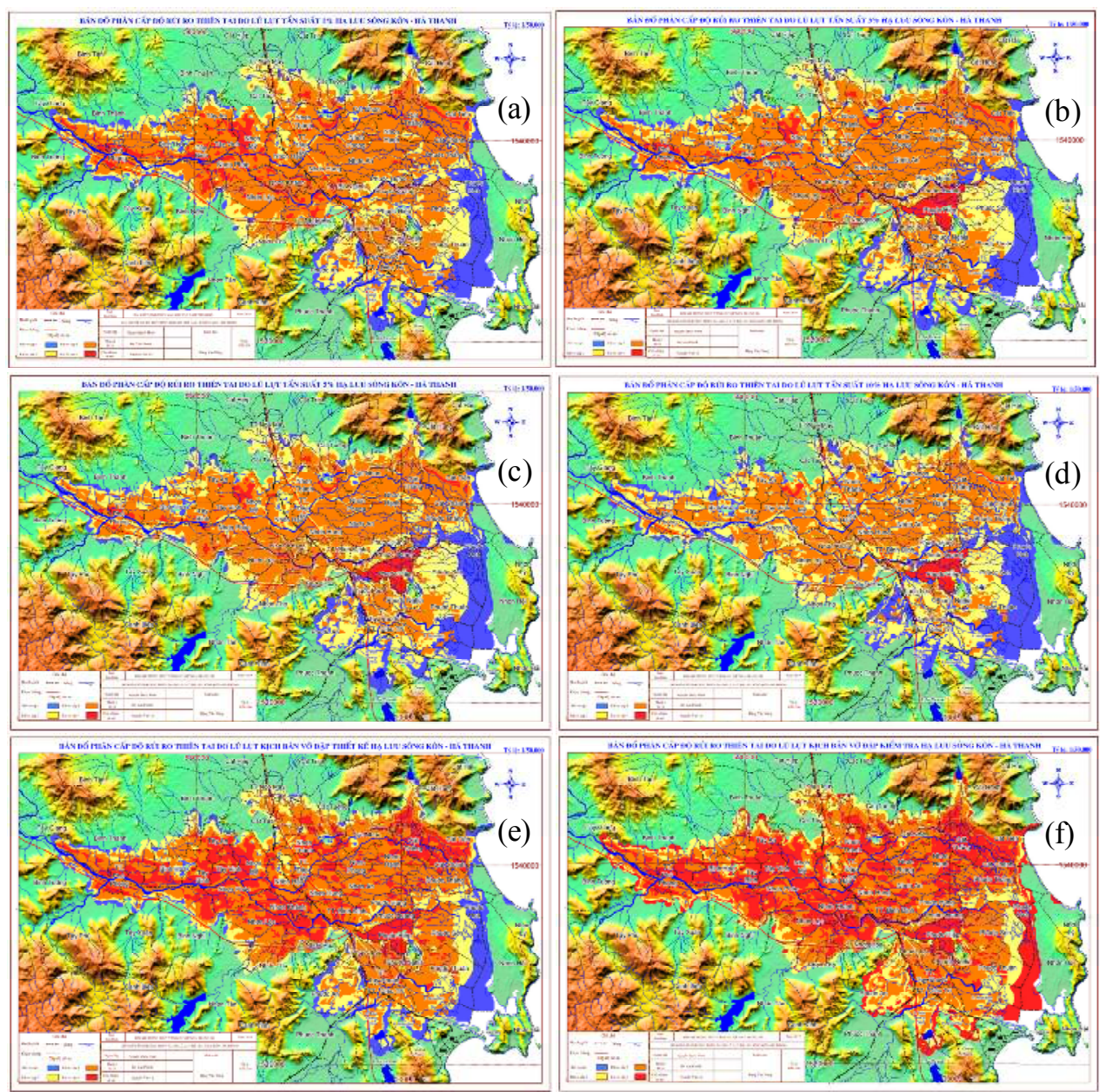

Hìn 9. Chi tiết cấp độ rủi ro do ngập lụt: (a) Tần suất 1\%; (b) Tần suất 3\%; (c) Tần suất 5\%; (d) Tần suất 10\%; (e) Ngập lụt võ̃ đập Định Bình lũ thiết kế; (f) Ngập lụt võ̃ đập Định Bình lũ kiểm tra

\section{Kết luận}

- Kết quả chi tiết như trên sẽ phát huy hiệu quả cao khi ứng dụng bản đồ chi tiết cấp độ rủi ro ngập lụt trong công tác cảnh báo và phòng chống ứng phó vùng hạ lưu sông Kôn - Hà Thanh.

- Kết quả chi tiết cấp độ rủi ro do ngập lụt hạ lưu sông Kôn - Hà Thanh dựa trên cơ sở khoa học và thực tiễn, góp phần bổ sung và hoàn thiện các phương pháp xác định, chi tiết cấp độ rủi ro do ngập lụt.

- Các dữ liệu sử dụng xác định bộ chỉ số rủi ro được số hóa trên bản đồ và tính toán theo các phương pháp đã được lựa chọn bằng công nghệ GIS cho kết quả trực quan, chi tiết và độ chính xác cao. Phương pháp chống chập bản đồ và cài đặt phương pháp tính toán với càng nhiều lớp thông tin, trường dữ liệu thì cho kết quả càng chi 


\title{
BÀI BÁO KHOA HỌC
}

tiết.

- Sử dụng công thức cộng theo quan điểm của IPCC phù hợp với hạ lưu sông Kôn - Hà Thanh. Sử dụng phương pháp AHP để xác trọng số trong

công thức cộng có tính khách quan và đánh giá được mức độ ảnh hưởng của từng thành phần trong công thức, từ đó xác định được chỉ số rủi ro phù hợp với thực tế.

\section{Tài liệu tham khảo}

1. Cấn Thu Văn (2015), Luận án Tiến sĩ Thủy văn học: Nghiên cứu xác lập co sở khoa học đánh giá tính dễ bị tổn thương do lũ lụt lưu vực sông Vũ Gia - Thu Bồn phục vụ quy hoạch phòng chống thiên tai. Đại học Khoa học Tự nhiên - Đại học Quốc gia Hà Nội.

2. Trần Thục (2015), Báo cáo đặc biệt của Việt Nam về quản lý rủi ro thiên tai và các hiện tuợng cực đoan nhằm thúc đẩy thích ứng với biến đổi khi hậu. NXB Tài nguyên - Môi trường và Bản đồ Việt Nam.

3. Nguyễn Thanh Sơn, Trần Ngọc Anh (2003), Xác xuất thống kê trong thủy văn. NXB Đại học Quốc gia Hà Nội.

4. Xây dưng bản đồ nguy cơ các sông tỉnh Bình Định (2009), Báo cáo tổng kết đề tài, Đài Khí tượng Thủy văn khu vực Nam Trung Bộ, Sở Khoa học và Công nghệ tỉnh Bình Định.

5. Nghiên cúu co sở khoa học và thực tiễn phục vu cảnh báo cấp độ rủi ro thiên tai do lũ và ngập lut cho các địa phưong thuộc khu vực Nam Trung Bộ. Áp dụng thí điểm cho lưu vực sông Kôn - Hà Thanh (2020), Báo cáo tổng kết đề tài, Đài Khí tượng Thủy văn khu vực Nam Trung Bộ chủ trì, Bộ Tài nguyên và Môi trường chủ quản.

6. IPCC (2012), Managing the Risks of Extreme Events and Disasters to Advance Climate Change Adaptation. A Special Report of Working Groups I and II of the Intergovernmental Panel on Climate Change (IPCC) [Field, C.B., V.Barros, T.F.Stocker, D.Qin, D.J.Dokken, K.L.Ebi). Cambridge University Press, Cambridge, UK, and New York, NY, USA.

7. Saaty, T. (2001). Decision Making with Dependence and Feed Back the Analytical Network Process. 2nd ed., University of Pittsburg, Pittsburg: RWS Publications.

8. Saaty, T. (1994), Fundamentals of Decision Making and Priority Theory, with the Analytical Hierarchy Process. Pittsburgh, PA.: RWS Publications.

\section{RESEARCHING ESTABLISHING FOR INUNDATION RISK LEVEL DETAIL MAP IN THE KÔN - HA THANH DOWNSTREAM RIVER}

\author{
Nguyen Van Ly ${ }^{1}$, Bui Van Chanh ${ }^{1}$ \\ ${ }^{1}$ Southern Central Regional Hydrometeorological Center
}

\begin{abstract}
The flood risk level in the Prime Minister's Decision No-44/2014/QĐ-TTg of August 15, 2014 is converted from the water level of hydrology stations so it is not detailed. Because, at the same water level but inundation depth is deferent between regions so inundation risk level is deferent. Beside, at the same inundation depth but socioeconomic is deferent between regions so inundation risk level is deferent too. Therefor, need establishing inundation risk level detail map for advancing reliability about warning inundation risk level. This researching, experimented establishing inundation risk level detail map in the Kôn - Ha Thanh downstream river based on the Decision No-44 and risk index detail based on the IPCC of perspective, the AHP of method. Inundation risk index detail map in the Kôn - Ha Thanh downstream river is established by inundation detail map and sociology survey data. Inundation scenario maps in the Kôn - Ha Thanh downstream river and sociology survey data are combined to establish inundation risk level detail map for frequency 1\%, 3\%, 5\%, 10\%, dam break of Dinh Binh with design flood and test flood.
\end{abstract}

Keywords: Inundation risk, Risk level, Kon - Ha Thanh River. 